\title{
Effectiveness analysis of resistance and tolerance to infection
}

\author{
Johann C Detilleux
}

\begin{abstract}
Background: Tolerance and resistance provide animals with two distinct strategies to fight infectious pathogens and may exhibit different evolutionary dynamics. However, few studies have investigated these mechanisms in the case of animal diseases under commercial constraints.

Methods: The paper proposes a method to simultaneously describe (1) the dynamics of transmission of a contagious pathogen between animals, (2) the growth and death of the pathogen within infected hosts and (3) the effects on their performances. The effectiveness of increasing individual levels of tolerance and resistance is evaluated by the number of infected animals and the performance at the population level.
\end{abstract}

Results: The model is applied to a particular set of parameters and different combinations of values. Given these imputed values, it is shown that higher levels of individual tolerance should be more effective than increased levels of resistance in commercial populations. As a practical example, a method is proposed to measure levels of animal tolerance to bovine mastitis.

Conclusions: The model provides a general framework and some tools to maximize health and performances of a population under infection. Limits and assumptions of the model are clearly identified so it can be improved for different epidemiological settings.

\section{Background}

The breeding objective in most livestock species is to increase profit by improving performance efficiency. One way to reach this objective is to improve the animals' health, for example, through the implementation of appropriate management methods (e.g. chemotherapy, vaccination, and control of disease vectors). A more sustainable method consists in taking advantage, by selective breeding, of the within-breed variation that exists in the mechanisms of defenses against infectious pathogens [1]. Indeed, hosts have evolved resistance and tolerance defenses [2], thus breeders may choose, as progenitors, animals with the highest levels of resistance, tolerance, or both. One the one hand, resistance is the ability of the host to reduce the success of infection or to increase the rate of clearance of the pathogens. On the other hand, tolerance is the ability to reduce the detrimental effects of the pathogens on the performances of the hosts, either directly or by limiting

Correspondence: jdetilleux@ulg.ac.be

Quantitative Genetics Group, Faculty of Veterinary Medicine, University of Liège, Liège, Belgium immunopathological mechanisms [3]. The rate of transmission diminishes naturally among resistant hosts but not necessarily among tolerant ones, as these harbor the pathogen with no or moderate loss in performance [4].

Resistance and tolerance are associated with fitness costs, which arise from the diversion of limiting resources away from biological processes related to performance [5]. If these costs are too high, they may outweigh the effectiveness of the chosen strategy. Direct evidence of such costs can be found in experiments in insects [6], rainbow trout [7], crustaceans [8], wild birds [9] and mice [10].

To decide whether improving resistance, tolerance, neither, or both is the most effective strategy, it is proposed to (1) characterize the dynamics of the pathogens within and between hosts in the population under study, (2) evaluate the impact of the infection on the performances of the population, and (3) choose the most effective strategy. The goal of this study is to illustrate the methodology with a non-lethal micro-parasitic disease in a population where hosts have different levels of resistance to multiplication of the pathogen and 
different levels of tolerance to damages induced directly by the pathogens.

\section{Methods \\ Pathogen dynamics}

The model chosen here to depict the dynamics of transmission of the infection in a herd is a stochastic version of the SIS (S for susceptible, I for infected) model for the spread of a disease in a closed population of $\mathrm{N}$ individuals [11]. This model is appropriate for infections with no permanent immunity after recovery, i.e. individuals are susceptible to the infection, potentially get infected, may recover and become susceptible again. The time-scale of the disease process is assumed to be short compared to the life length of the host and no demographic turnover (natural birth or death) is considered. The area occupied by parasites and hosts is constant, so that numbers and densities coincide. There is only a single non-evolving pathogen species within infected hosts. Once infected, hosts are immediately able to infect other individuals (no latent period). Within the host, the number of pathogens increases following a sigmoidal growth curve and is directly related to the number of immune constituents of the host response to the pathogen, with no distinction between innate and specific immunity. Recovered hosts are as susceptible to infection as naïve hosts and re-exposure does not accelerate development of the disease.

In mathematical terms, the process is described by a continuous time Markov chain, $\left\{\mathrm{C}_{\mathrm{t}}^{\mathrm{i}} ; \mathrm{t}=0\right.$ to $\mathrm{T}, \mathrm{i}=1$ to $\mathrm{N}$ \}, where $\mathrm{C}_{\mathrm{t}}^{\mathrm{i}}$ denotes the number of pathogens in the $\mathrm{i}^{\text {th }}$ host at time $\mathrm{t}$. Units of time are chosen arbitrarily. The chain has three transition probabilities (over a small time interval $\Delta t$ ) reflecting the three events, i.e. invasion of a new host by the pathogen, its multiplication and its killing by the immune response of the host.

The first transition probability is the probability the $\mathrm{i}^{\text {th }}$ susceptible host is infected by $\mathrm{C}_{\min }$ pathogens:

$$
\begin{aligned}
\operatorname{Pr}\left(C_{(\mathrm{t}+\Delta \mathrm{t})}^{\mathrm{i}}\right) & \left.=\mathrm{C}_{\min } \mid \mathrm{C}_{\mathrm{t}}^{\mathrm{i}}=0\right) \\
& =\beta \mathrm{I}_{\mathrm{t}} / \mathrm{N} \Delta \mathrm{t}+\mathrm{o}(\Delta \mathrm{t})
\end{aligned}
$$

where $o(\Delta t)$ tends to 0 when $\Delta t$ is small, $C_{\min }$ is the minimum number of pathogens necessary to have infection, $\beta$ is the per-capita rate of successful transmission of $C_{\text {min }}$ pathogens from an infectious host to a susceptible host upon contact with an infectious individual and during $\Delta \mathrm{t}$, and $\mathrm{I}_{\mathrm{t}}$ is the number of infectious hosts with which the $\mathrm{i}^{\text {th }}$ susceptible has contact.

The second transition probability is the probability that a pathogen in an infected host gives birth to $C_{\min }$ new offspring, such that this host becomes infectious:

$$
\begin{aligned}
\operatorname{Pr}\left(C^{\mathrm{i}}(\mathrm{t}+\Delta \mathrm{t})\right. & \left.=\mathrm{c}+\mathrm{C}_{\min } \mid \mathrm{C}_{\mathrm{t}}^{\mathrm{i}}=\mathrm{c}\right) \\
& =\mathrm{C}_{\mathrm{t}}^{\mathrm{i}}\left\{\gamma\left[1-\left(\mathrm{C}_{\mathrm{t}}^{\mathrm{i}} / \mathrm{C}^{\mathrm{Max}}\right)\right]\right\} \Delta \mathrm{t}+\mathrm{o}(\Delta \mathrm{t}),
\end{aligned}
$$

where $\gamma$ is the pathogen growth rate. Right after becoming infected, pathogen growth in a host is approximately exponential but it slows down as it reaches a maximum $\left(\mathrm{C}^{\mathrm{Max}}\right)$, at which it stops.

The last transition probability is the probability that $\mathrm{C}_{\text {min }}$ pathogens are killed within the host:

$$
\begin{aligned}
\operatorname{Pr}\left(C_{(t+\Delta t)}^{\mathrm{i}}\right. & \left.=c-C_{\min } \mid C_{t}^{i}=c\right) \\
& =\left\{\rho^{i} \mu R_{t}^{i} C_{t}^{i}\right\} \Delta t+o(\Delta t) .
\end{aligned}
$$

This equation follows from the dynamics between pathogens and immune factors, as observed in experimental studies $[12,13]$. Parameter $\mu$ represents the maximum number of pathogens killed for each unit of $R_{t}^{i}$, with $R_{t}{ }_{t}$ being a generic index related to the number, at time $t$, of the different types of immune factors specific for that pathogen. Because the main interest is on the number of pathogens, the complexity of the immune response is greatly simplified when $R_{t}{ }_{t}$ increases at a rate $\left(h^{i}\right)$ that is constant across time. The scaling parameter $\rho^{\mathrm{i}}$ varies from 0 to 1 and represents the extra investment in resistance of the $i^{\text {th }}$ host with respect to $\mu$. When $C_{t}^{i}$ drops below $C_{\text {min }}$, the infection is assumed to be cleared.

The Markov chain was simulated using the Gillespie algorithm [14], which essentially uses exponential waiting times between events. For all simulations, it was assumed that two individuals in the population were initially infected. Simulation steps were executed until $t$ reaches $\mathrm{T}$ units of time (= one replicate) and repeated over 50 replicates. Each cycle took around 4 hours to complete, so the population size was limited at 30 individuals, which is the average size of most dairy herds in the Walloon region of Belgium.

\section{Individual performance}

The performance of an infected host decreases proportionally to the number of pathogens $\left(C_{t}^{i}\right)$ and to investments of the host in tolerance [15]:

$$
P_{t}^{i}=P_{t=0}^{i}-C_{t}^{i} \omega\left(1-\lambda^{i}\right),
$$

where $\mathrm{P}_{t}^{\mathrm{i}}$ is the performance of the $\mathrm{i}^{\text {th }}$ host at time $\mathrm{t}$, when it is infected with $C^{i}{ }_{t}$ pathogens, $\omega$ is the maximum amount of performance lost per pathogen (virulence). The parameter $\lambda^{\mathrm{i}}$ is a scaling parameter representing the extra investment in tolerance. If $\lambda^{i}=1$, the host is completely tolerant and produces at a level 
identical to the one without infection. If $\lambda^{\mathrm{i}}=0$, the host is not tolerant to the deleterious effects of the pathogen.

Hosts invest part of their constitutive resources to resist or tolerate the pathogens and costs are assumed proportional to the investments in both types of defense. They are combined in an additive way:

$$
P_{t=0}^{i}=P^{M a x}\left(1-\rho^{i} c_{\rho}^{i}-\lambda^{i} c_{\lambda}^{i}\right),
$$

where $\mathrm{P}^{\mathrm{Max}}$ is the totality of the resources available to the host to insure performance (e.g., production, reproduction, work) and to cope with an infection (resistance and tolerance). If no extra-investments are put in resistance and tolerance, all resources are allocated to insure the highest achievable level of performance in the absence of infection. Parameter $c_{\rho}^{\mathrm{i}}{ }_{\rho}$ is the marginal cost of resistance and $c_{\lambda}^{i}$ is the marginal cost of tolerance (in units of performance). Values for both costs are constrained such that the factor within brackets remains positive $\left(\rho^{\mathrm{i}} \mathrm{c}_{\rho}^{\mathrm{i}}+\lambda^{\mathrm{i}} \mathrm{c}_{\lambda}^{\mathrm{i}} \leq 1\right)$. A constraint was also set to insure $\mathrm{P}_{\mathrm{t}}^{\mathrm{i}}$ (equation 4) remains positive or null in totally non-tolerant individuals infected with $\mathrm{K}$ pathogens: $\omega \leq$ $\mathrm{P}^{\operatorname{Max}}\left(1-\rho^{\mathrm{i}} \mathrm{c}_{\rho}^{\mathrm{i}}\right) / \mathrm{K}$.

Typical patterns in performance as a function of number of pathogens are shown schematically in Figure 1 to illustrate the different ways resources can be allocated between resistance, tolerance and performance (costs are assumed equal for resistance and tolerance). Performances of hosts allocating none of the available resources to resistance and tolerance are the highest at the start of infection $\left(\mathrm{P}_{\mathrm{t}}=0=\mathrm{P}^{\mathrm{Max}}\right)$ and decrease as $\mathrm{C}_{\mathrm{t}}$ increases. Numbers of pathogens remain below 20 among resistant hosts, and performances of tolerant hosts do not decline with increasing parasite burden.

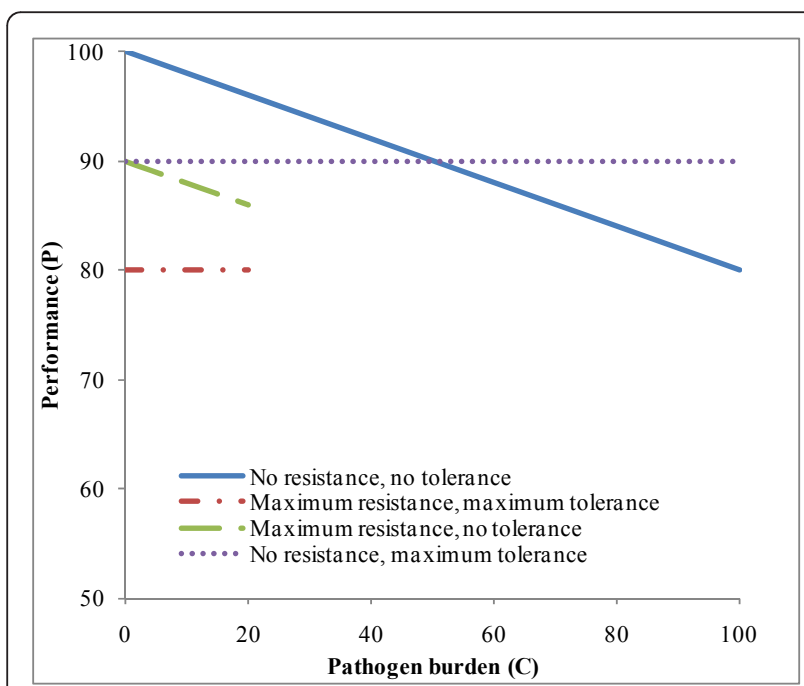

Figure 1 Schematic representation of the impact of resource allocation on performance $(P)$ and number of pathogens $(C)$.

\section{Effectiveness analysis}

The most profitable strategy, i.e. the one that will insure the lowest number of infected animals or the highest performance of the population, or both, was identified by weighing the allowed extra investments in resistance, tolerance, or both, against the effectiveness of each of these alternatives.

Effectiveness was computed by comparing populations under the same infection process but in which animals invest ('yes' population) or not ('no' populations) in resistance, tolerance, or both. To do so, the number of infected hosts $\left(\mathrm{I}_{\mathrm{t}}\right)$ and the overall performance $\left(\mathrm{P}_{\mathrm{t}}=\right.$ $\left.\Sigma_{\mathrm{i}}=1, \mathrm{~N} \mathrm{P}_{\mathrm{t}}^{\mathrm{i}}\right)$ were followed across time, and the area under the curves of $\mathrm{P}_{t}\left(\mathrm{AUC} \mathrm{C}_{\mathrm{P}}\right)$ and $\mathrm{I}_{\mathrm{t}}\left(\mathrm{AUC}_{\mathrm{I}}\right)$ were obtained for $t=0$ to $T$ with the spline method of the procedure Expand of SAS ${ }^{\circledR}$ [16]. Subsequently, the incremental effects $\left(\Delta \mathrm{E}_{\mathrm{I}}\right.$ and $\left.\Delta \mathrm{E}_{\mathrm{P}}\right)$ were computed as the difference between corresponding 'yes' and 'no' populations: $\Delta \mathrm{E}_{\mathrm{I}}=\mathrm{AUC}_{\mathrm{I}}^{\mathrm{no}}-\mathrm{AUC}_{\mathrm{I}}^{\mathrm{yes}}$, and $\Delta \mathrm{E}_{\mathrm{P}}=\mathrm{AUC}_{\mathrm{P}}{ }^{\text {yes }}$ $\mathrm{AUC}_{\mathrm{P}}{ }^{\mathrm{no}}$. Then, the most effective alternative was identified as the one with the highest values for $\Delta \mathrm{E}_{\mathrm{I}}$ and $\Delta \mathrm{E}_{\mathrm{P}}$.

Incremental effects were calculated for different sets of parameters (Table 1). Two transmission rates were considered, with $\beta=0.1$ and $\beta=0.5$, which correspond to a new infection per 10 and 2 effective contacts, respectively. The minimum number of pathogens was set to $C_{\min }=10$ and the maximum to $C^{\mathrm{Max}}=500$. The growth rate $(\gamma)$ was set at 0.5 new pathogens for each existing one and the value for $\mu$ was set to 0.25 or 1.0 to obtain killing rates equal to half or twice the pathogen growth rate. A convenient value of 100 was given to $\mathrm{P}^{\mathrm{Max}}$, while virulence $(\omega)$ was set at 0.1 or 0.2 units of performance lost per pathogen present. Individual extra investments in resistance and tolerance were drawn from uniform distributions with different extreme values to have low $(\mathrm{U}[0$, $0.5])$, average $(U[0,1])$, or high $(U[0.9,1])$ levels of investments. Associated costs were drawn from uniform distributions within the allowable limits imposed by equations (4) and (5): $\mathrm{U}[0,0.1], \mathrm{U}[0.1,0.2]$, and $\mathrm{U}[0.2,0.5]$.

Finally, effects of low, average and high levels of extrainvestments in resistance and tolerance on $\Delta \mathrm{E}_{\mathrm{I}}$ and $\Delta \mathrm{E}_{\mathrm{P}}$ were quantified using fixed linear models (proc GLM on SAS $^{\circledR}[16]$ ) that also contained the effects of $\beta, \mu$, and $\omega$ for the characteristics of the pathogen, the averages at the population level of $h^{i}, c_{\rho}^{i}$ and $c_{\lambda}^{i}$ for the characteristics of the hosts, and all first-order interactions. The resulting least-squares estimates were used to identify epidemiological situations for which investments in tolerance, resistance or both were effective.

\section{Results}

\section{Within-host pathogen dynamics}

The number of pathogens within a host is shown in Figure 2 for 10 animals in a 'no' population with the 
Table 1 Model parameters and their values

\begin{tabular}{|c|c|c|}
\hline Symbol & Description & Values \\
\hline$\overline{P_{t}^{i}}$ & Performance for animal $\mathrm{i}$ at time $\mathrm{t}$ & \\
\hline$C_{t}^{i}$ & Pathogen number in animal $\mathrm{i}$ at time $\mathrm{t}$ & \\
\hline$R_{t}^{i}$ & Immune response in animal $\mathrm{i}$ at time $\mathrm{t}$ & \\
\hline $\mathrm{I}_{\mathrm{t}}$ & Number of infected animals in the population at time $t$ & \\
\hline$P_{t}$ & Population performance at time $\mathrm{t}$ & \\
\hline$\Delta \mathrm{E}_{\mathrm{p}}$ & Incremental effectiveness for $P_{t}$ over the $T$ period & \\
\hline$\Delta \mathrm{E}_{1}$ & Incremental effectiveness for $I_{t}$ over the $T$ period & \\
\hline N & Population size & 30 \\
\hline $\mathrm{T}$ & Time duration & 300 \\
\hline$C_{\min }$ & Pathogen number necessary for infection & 10 \\
\hline$C^{\operatorname{Max}}$ & Maximum number of pathogens & 500 \\
\hline$P^{\operatorname{Max}}$ & Maximum performance & 100 \\
\hline$\gamma$ & Per-capita pathogen growth rate & 0.5 \\
\hline$\beta$ & Transmission rate & $0.1 ; 0.5$ \\
\hline$\mu$ & Maximum per-capita pathogen killing rate & $0.25 ; 1.0$ \\
\hline$\omega$ & Maximum performance loss per pathogen & $0.1 ; 0.2$ \\
\hline$C_{\rho}^{i}$ & Marginal costs of resistance & $\cup[0,0.1] ; \cup[0.1,0.2] ; \cup[0.2,0.5]$ \\
\hline$c_{\lambda}^{i}$ & Marginal costs of tolerance & $\cup[0,0.1] ; \cup[0.1,0.2] ; \cup[0.2,0.5]$ \\
\hline$\rho^{i}$ & Extra investment in resistance & $\cup[0,1] ; \cup[0,0.5] ; \cup[0.9,1]$ \\
\hline$\lambda^{i}$ & Extra investment in tolerance & $\cup[0,1] ; \cup[0,0.5] ; \cup[0.9,1]$ \\
\hline$h^{i}$ & Rate of increase for the immune index & $\cup[0,0.001] ; \cup[0,0.01] ; \cup[0,0.1]$ \\
\hline
\end{tabular}

following characteristics: $\beta=0.5 ; \mu=0.1 ; \omega=0.1 ; \mathrm{h}^{\mathrm{i}} \sim$ $\mathrm{U}[0,0.001]$, and $\rho^{\mathrm{i}}=\lambda^{\mathrm{i}}=0$ for $\mathrm{i}=1$ to $\mathrm{N}$. The duration and the number of pathogens generated were approximately the same for all animals because they depended on $\gamma=0.5$ (equation 2). However, the stochastic nature

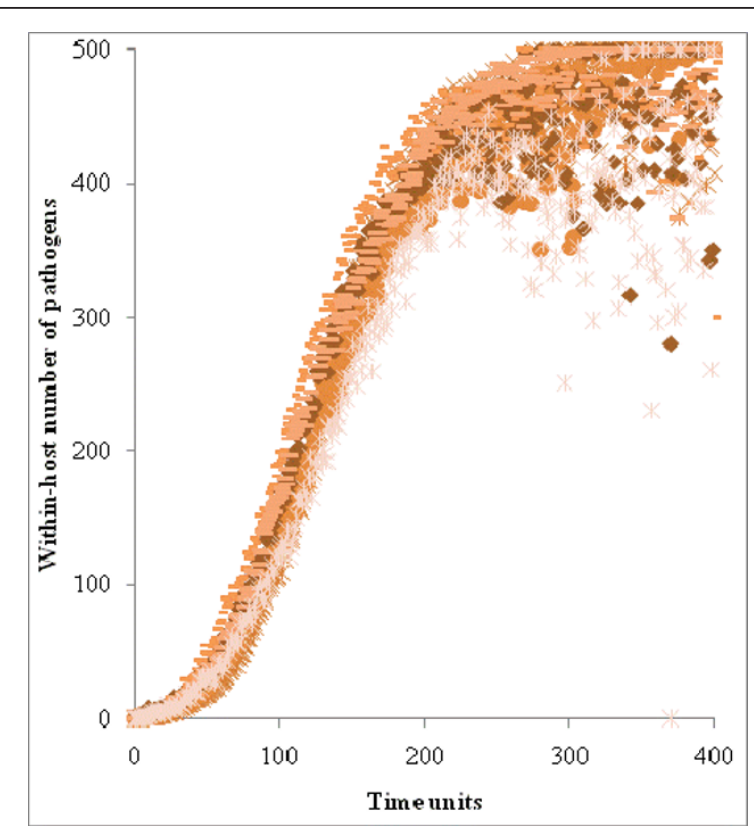

Figure 2 Number of pathogens across time for 10 completely susceptible hosts. of the simulation resulted in a cloud of points for each $\mathrm{C}_{\mathrm{t}}^{\mathrm{i}}$. On average, $\mathrm{C}^{\mathrm{Max}}$ was reached after 300 time units, so it was used as the upper limit for $\mathrm{T}$ because the Gillespie algorithm was slow to converge and because $\mathrm{T}=$ 300 insured the steady value $C^{\mathrm{Max}}$ was reached among completely non-resistant hosts.

In Figure 3, the dynamics in $\mathrm{C}_{\mathrm{t}}^{\mathrm{i}}$ and $\mathrm{P}_{\mathrm{t}}^{\mathrm{i}}$ are shown for four individuals with different investments and costs of resistance and tolerance, and for an infection with $\beta=$ $0.5, \gamma=0.5, \omega=0.2, \mathrm{~h}^{\mathrm{i}} \sim \mathrm{U}[0,0.1]$, and $\mu=0.25$. When both $\rho^{\mathrm{i}}$ and $\lambda^{\mathrm{i}}$ were high, $\mathrm{C}_{\mathrm{t}}^{\mathrm{i}}$ remained low and $\mathrm{P}_{\mathrm{t}}^{\mathrm{i}}$ did not change much across time (individuals $\square$ or + ). Conversely, when $\rho^{i}$ was low, $C^{i}$ increased up to its maximum and the associated individual performance decreased (individual $\circ$ in Figure 3). Between these extremes, a wide range of different situations occurred. Initial performance $\left(\mathrm{P}_{0}\right)$ varied according to the costs and extra investments in tolerance and resistance (equation 3).

\section{Between-host pathogen dynamics}

The number of infected hosts $\left(\mathrm{I}_{\mathrm{t}}\right)$ and the overall performance $\left(\mathrm{P}_{t}\right)$ are given in Figure 4 as percentages of their maximum values ( $\mathrm{N}$ and $\mathrm{P}^{\mathrm{Max}}$, respectively) and for an infection with $\beta=0.5, \gamma=0.5, \omega=0.1$, and $\mu=0.25$. At $\mathrm{T}=300$, all individuals in the 'no' population (Figure 4a) were infected (with the exception of one) and the overall performance was close to $50 \%$, which is the minimum expected from equation 5 when all 


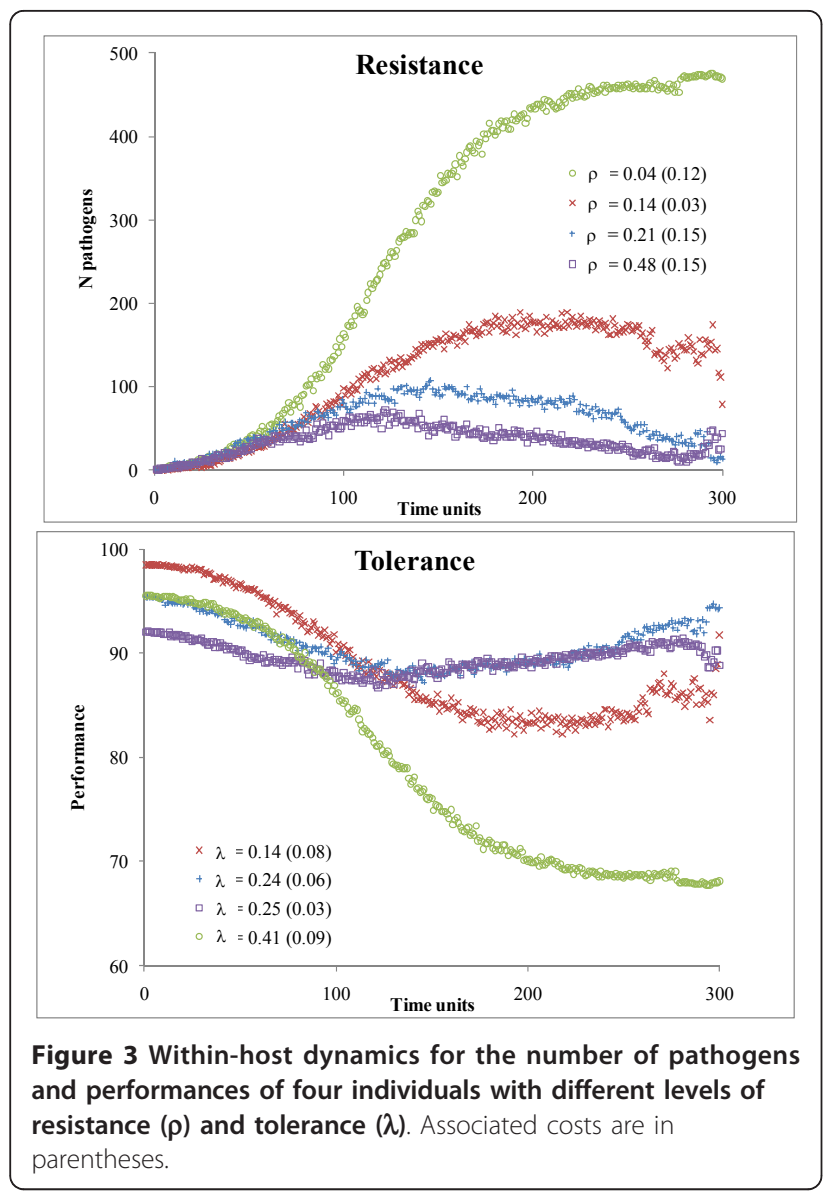

animals have zero tolerance and are infected with $C^{\text {Max }}$ pathogens.

When individuals invested more in resistance, only a fraction of the population got infected and $\mathrm{AUC}_{\mathrm{I}}$ was low. For example, $\mathrm{AUC}_{\mathrm{I}}$ decreased from 22,720 to 19,379 and 13,851 infected hosts in Figures $4 \mathrm{~b}(\rho=0.22), 4 \mathrm{e}(\rho=$ $0.46)$, and $4 \mathrm{~h}(\rho=0.94)$, respectively. When the average level of extra investments in tolerance was high (around 0.95), the impact of $I_{t}$ on $P_{t}$ was almost zero (Figures $4 \mathrm{~d}, g$ and $4 \mathrm{j})$. Otherwise, $P_{t}$ decreased as $I_{t}$ increased, especially for low levels of tolerance (Figures $4 \mathrm{~b}$,e and $4 \mathrm{~h}$ ). This should have translated in an increase in $\mathrm{AUC}_{\mathrm{P}}$ but, in this particular population, costs associated with tolerance were high (around 0.15) and initial performance was low. For example, $\mathrm{P}_{0}$ averaged 79.8 in Figure $4 \mathrm{~g}\left(\lambda=0.95\right.$; $\mathrm{AUC}_{\mathrm{P}}=$ $23,509)$ and 90.4 in Figure 4e $\left(\lambda=0.25 ; \mathrm{AUC}_{\mathrm{P}}=24,779\right)$.

\section{Effectiveness analyses}

Values of $\Delta \mathrm{E}_{\mathrm{P}}$ and $\Delta \mathrm{E}_{\mathrm{I}}$ obtained for each combination of the parameters of Table 1 are shown in relation to $\rho$ and $\lambda$ in Figure 5. Each dot corresponds to one specific combination of the parameter values. Effective combinations, those associated with both $\Delta \mathrm{E}_{\mathrm{P}}>0$ and $\Delta \mathrm{E}_{\mathrm{I}}>0$, represented $75.7 \%$ of all combinations. There was a tendency for $\Delta \mathrm{E}_{\mathrm{I}}$ and $\Delta \mathrm{E}_{\mathrm{P}}$ to increase with increasing values for $\rho$ and $\lambda$, respectively. However, there were also combinations of parameters for which high values for $\rho$ or $\lambda$ were not effective, as revealed by the analysis of variance.

Results from the analysis of variance identified significant $(\mathrm{p}<0.01)$ effects of $\rho^{\mathrm{i}}, \mathrm{c}_{\rho}, \mathrm{h}^{\mathrm{i}}$, and $\mu$ on $\Delta \mathrm{E}_{\mathrm{I}}$, and of $\lambda, c_{\lambda}, \beta$, and $\omega$ on $\Delta E_{p}$. All first-order interactions were non-significant $(\mathrm{p}>0.10)$. Incremental effects are given in Tables 2 and 3 for selected combinations. Overall, $\Delta \mathrm{E}_{\mathrm{P}}$ was greater for higher values of $\lambda$ but, for moderately virulent $(\omega=0.1)$ and slow spreading $(\beta=0.1)$ diseases, investments in tolerance were low or ineffective unless they incurred at low costs (Table 2). Investing in resistance (Table 3 ) was effective for infections that elicited moderate to high but not low $\left(\mathrm{h}^{\mathrm{i}} \sim \mathrm{U}[0,0.001]\right)$ immune responses in the hosts (unless levels of resistance were high).

\section{Discussion}

A general framework is proposed to provide insights into the effects of improved resistance and tolerance on the performance and size of an infected population. A clear distinction is made between effects of resistance on multiplication of the pathogen and effects of tolerance on damages induced by the pathogens. Hosts differ in the costs they incur to insure their particular levels of resistance and tolerance, and in the intensity of the response they mount against pathogens. Pathogens differ in their speed of spread between hosts, in virulence, and in the intensity of the response they elicit in the hosts. However, to be useful, the model must be validated and its limits and assumptions must be clarified, as will be discussed in the following, with examples mostly related to bovine mastitis.

\section{Validation of the model}

Model validation usually takes the form of a comparison between model outputs and real data but this was not possible here because reliable field data are scarce, difficult to measure or imprecisely defined $[17,18]$. For example, estimates of costs associated with resistance and tolerance are limited in animals, in contrast to plants (see review by [19]). Tolerance has often been measured imprecisely as the overall ability to maintain fitness in the face of infection, irrespective of parasite burden. For example, cows infected with $E$. coli have been classified as moderate and severe responders according to milk production loss in the nonchallenged quarters [20]. In this case, it is in reality a measure of the combined effects of resistance and tolerance [4]. It was also a deliberate choice to present a generic model because parameters values are different among disease and host populations, so model outputs 

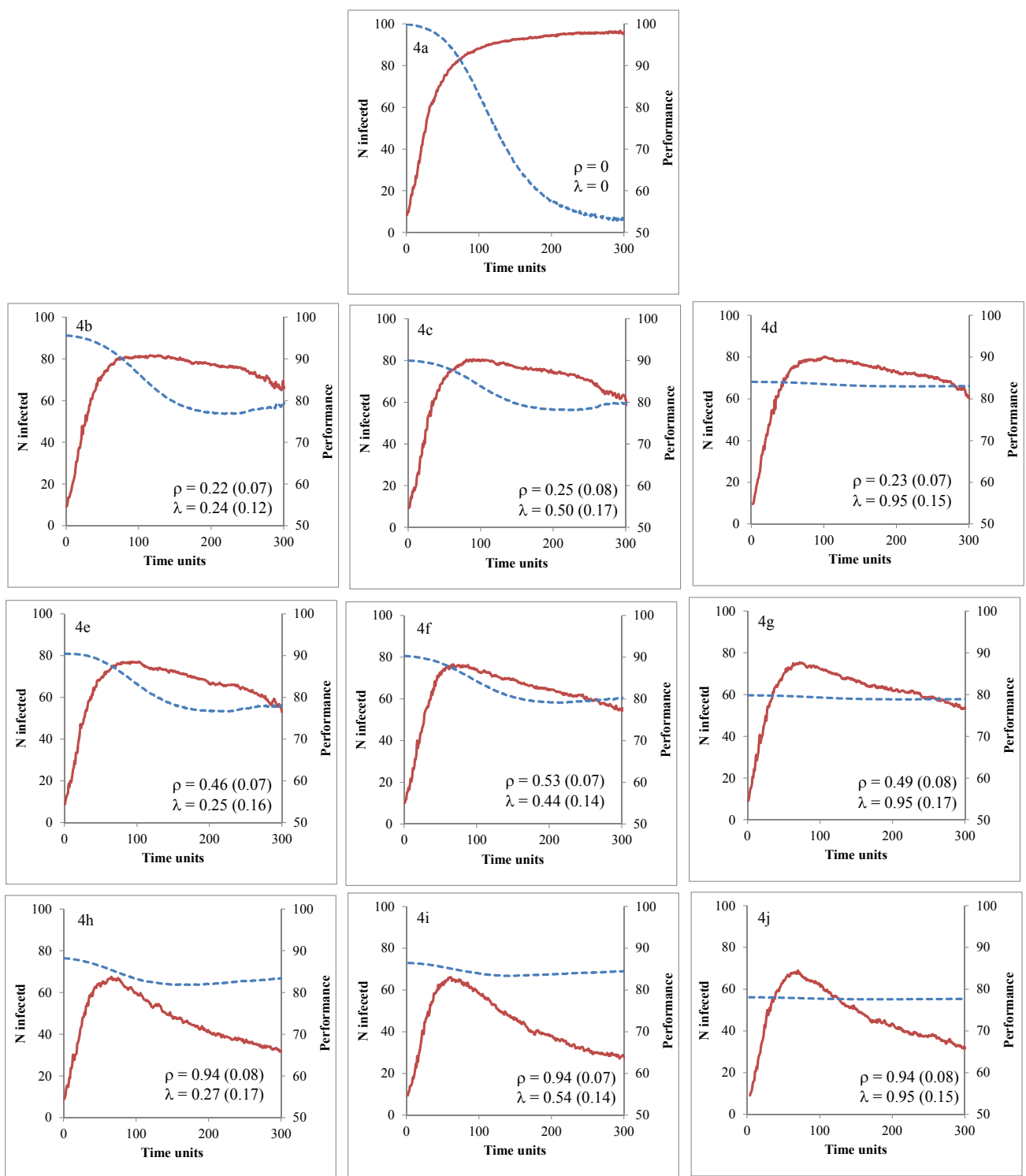

Figure 4 Number of infected individuals (solid line) and overall performance (broken line) in populations with different average values for levels of resistance $(\rho)$ and tolerance $(\lambda)$, and for their associated costs $\left(c_{\rho}\right.$ and $c_{\lambda}$ in parentheses). The values are expressed as percentages of their maxima.

for one specific disease may not apply to another disease. For example, transmission rates have been estimated at 0.20 to 1.50 per 1000 quarter-days at risk for S. uberis mastitis [21] but at 7 to 50 for S. aureus mastitis [22]. Similarly, killing rates have been estimated at 0.67 to $1.33 \times 10^{-8} \mathrm{~mL} /$ cell per min in milk of cows $[23,24]$ and at 1.64 to $1.76 \times 10^{-8} \mathrm{~mL} /$ neutrophil per min in dermis of rats inoculated with E. coli [13]. Model outputs will also depend on the virulence of the invading pathogens $(\omega)$, as exemplified by the different amount of milk loss at the first occurrence of clinical mastitis depending on bacteria species [25], and on the type of performance (e.g., yield, quality of products, or capacity for work) considered.

As an alternative form of validation, the dynamics of $\mathrm{C}_{\mathrm{t}}^{\mathrm{i}}$ and $\mathrm{P}_{\mathrm{t}}^{\mathrm{i}}$ at the individual, and of $\mathrm{I}_{\mathrm{t}}$ and $\mathrm{P}_{\mathrm{t}}$ at the herd levels were evaluated. For instance, as expected, $C_{t}{ }_{t}$ was lowest in resistant and $\mathrm{P}_{\mathrm{t}}^{\mathrm{i}}$ was highest in tolerant hosts (Figure 3), $\mathrm{P}_{\mathrm{t}}$ remained stable across time when tolerance of the hosts was at its highest level, and $\mathrm{I}_{t}$ decreased faster when resistance of hosts was at its highest level (Figure 4). Results from the analysis of variance also validated the model. The null value of $\Delta \mathrm{E}_{\mathrm{I}}$ for $\mathrm{h}^{\mathrm{i}} \sim \mathrm{U}[0,0.001]$ was sensible because, at this low rate, 

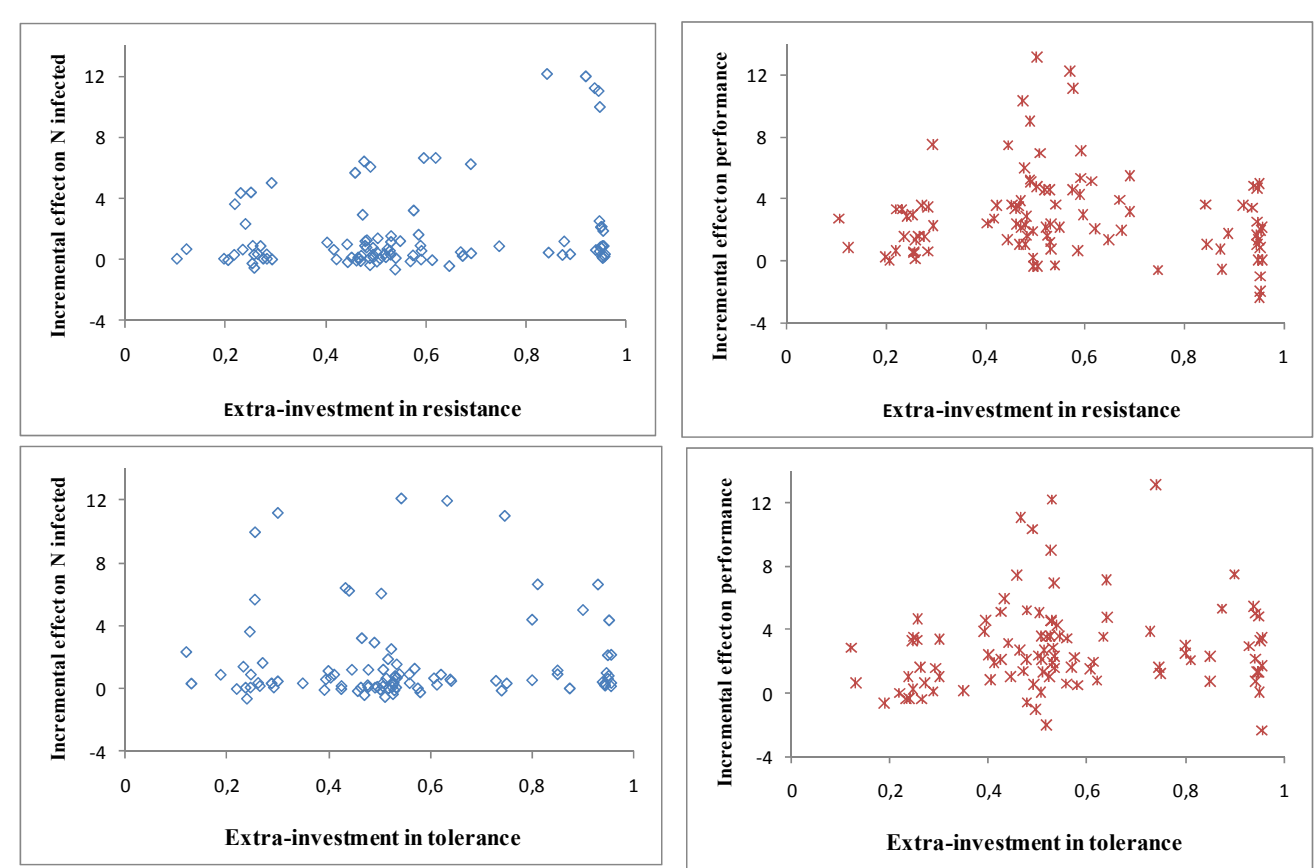

Figure 5 Incremental effectiveness for performance $\left(\Delta E_{p}\right)$ and number of infected individuals $\left(\Delta E_{1}\right)$ for different investments in resistance $(\rho)$ and tolerance $(\lambda)$ and for various characteristics of the infection (Table 1 ).

pathogens cannot be killed, regardless of how much was invested in resistance. The fact that $\beta$ did not affect $\Delta \mathrm{E}_{\mathrm{I}}$ may also be explained by the same transmission in 'yes' and 'no' populations, so $\mathrm{AUC}_{\mathrm{I}}{ }^{\text {yes }}$ was close to $\mathrm{AUC}_{\mathrm{I}}$ ' for any value of $\beta$. As a final example, $\Delta \mathrm{E}_{\mathrm{P}}$ was higher for $\beta=0.5$ than for $\beta=0.1$ because only few animals got infected with $\beta=0.1$, so improving tolerance of these few hosts was not beneficial at the population level.

\section{Limits and assumptions of the model}

The strategy to build this model followed the current trend in epidemiology to begin with simple models and

Table 2 Incremental effectiveness of the performance of the population $\left(\Delta E_{p}\right)$ associated to different investments in individual tolerance $\left(\lambda^{i}\right)$ and for selected values of $c_{\lambda_{\nu}}^{i}$ $\beta$ and $\omega$, as defined in Table 1

\begin{tabular}{|c|c|c|c|c|c|c|c|}
\hline \multicolumn{4}{|c|}{$\lambda^{i} \sim U[0,0.5]$} & \multicolumn{4}{|c|}{$\lambda^{i} \sim U[0.9,1]$} \\
\hline$c_{\lambda}^{i}$ & $\beta$ & $\omega$ & $\Delta \mathrm{E}_{\mathrm{P}}$ & $c_{\lambda}^{i}$ & $\beta$ & $\omega$ & $\overline{\Delta \mathrm{E}_{\mathrm{P}}}$ \\
\hline 0 & 0.1 & 0.1 & 1623 & 0 & 0.1 & 0.1 & 2974 \\
\hline$U[0.2,0.5]$ & 0.1 & 0.1 & -628 & $U[0.2,0.5]$ & 0.1 & 0.1 & 722 \\
\hline 0 & 0.1 & 0.2 & 5635 & 0 & 0.1 & 0.2 & 6986 \\
\hline$U[0.2,0.5]$ & 0.1 & 0.2 & 3383 & $U[0.2,0.5]$ & 0.1 & 0.2 & 4734 \\
\hline 0 & 0.5 & 0.1 & 4198 & 0 & 0.5 & 0.1 & 5549 \\
\hline$U[0.2,0.5]$ & 0.5 & 0.1 & 1946 & $U[0.2,0.5]$ & 0.5 & 0.1 & 3297 \\
\hline 0 & 0.5 & 0.2 & 8210 & 0 & 0.5 & 0.2 & 9561 \\
\hline$U[0.2,0.5]$ & 0.5 & 0.2 & 5958 & $U[0.2,0.5]$ & 0.5 & 0.2 & 7309 \\
\hline
\end{tabular}

to add complexity only if the model fails to reproduce plausible epidemiological behaviors [26]. Several assumptions were made, some of which have been confirmed previously. One assumption was that available resources are partitioned between performance, resistance and tolerance. Indeed, experiences in poultry [27] and other species [28] have shown that individuals differ in their ability to allocate resources to their needs. This is also one of the factors evoked to explain the increased susceptibility of high yielding dairy cows to mastitis [29]. Lack of resources may lead to vicious cycles because hosts in poor condition are more susceptible to higher pathogen occurrence and infection intensity, which further weaken the condition of the host [30]. Another assumption is that investments in resistance and tolerance are linked through the constraint in equation 4 and this has been confirmed by [2], where a negative relationship was found between resistance and tolerance in rodent malaria.

Some assumptions of the model could also be relaxed with more complex equations that have been used in models examining the effects of mixed infection [21], infectious dose [31] and vaccination/treatment [32] on transmission dynamics. Resistance could vary as a function of exposure to disease [33]. Availability of external resource can vary across time, as in Doesch-Wilson et al. [34]. In the model used here, individual infectious contacts were assumed independent and at random but models with heterogeneous mixing [35] and that 
Table 3 Incremental effectiveness of the number of infected $\left(\Delta \mathrm{E}_{1}\right)$ associated to different investments in individual resistance $\left(\rho^{i}\right)$ and for selected values of $c_{\rho}^{i}, \mu$ and $h^{i}$, as defined in Table 1

\begin{tabular}{|c|c|c|c|c|c|c|c|}
\hline \multirow[b]{2}{*}{$c_{\rho}^{i}$} & \multicolumn{2}{|c|}{$\rho^{i} \sim U[0,0.5]$} & \multirow[b]{2}{*}{$\Delta \mathrm{E}_{\mathrm{I}}$} & \multicolumn{4}{|c|}{$\rho^{i} \sim U[0.9,1]$} \\
\hline & $h^{i}$ & $\mu$ & & $c_{\rho}^{i}$ & $h^{i}$ & $\mu$ & $\Delta \mathrm{E}_{\mathrm{l}}$ \\
\hline $\mathrm{U}[0.2,0.5]$ & $\cup[0,0.001]$ & 0.25 & -808 & $U[0.2,0.5]$ & $\cup[0,0.001]$ & 0.25 & 1509 \\
\hline 0 & $U[0,0.001]$ & 0.25 & -1215 & 0 & $U[0,0.001]$ & 0.25 & 1103 \\
\hline$U[0.2,0.5]$ & $\cup[0,0.001]$ & 1 & -127 & $U[0.2,0.5]$ & $\cup[0,0.001]$ & 1 & 2191 \\
\hline 0 & $\cup[0,0.001]$ & 1 & -533 & 0 & $\cup[0,0.001]$ & 1 & 1784 \\
\hline$U[0.2,0.5]$ & $\cup[0,0.1]$ & 0.25 & 5607 & $U[0.2,0.5]$ & $\cup[0,0.1]$ & 0.25 & 7925 \\
\hline 0 & $\cup[0,0.1]$ & 0.25 & 5201 & 0 & $\cup[0,0.1]$ & 0.25 & 7518 \\
\hline$U[0.2,0.5]$ & $\cup[0,0.1]$ & 1 & 6289 & $U[0.2,0.5]$ & $\cup[0,0.1]$ & 1 & 8607 \\
\hline 0 & $U[0,0.1]$ & 1 & 5882 & 0 & $U[0,0.1]$ & 1 & 8200 \\
\hline
\end{tabular}

consider genetic susceptibility among relatives [36,37] may be more appropriate. The course of infection within hosts can also be modelled more accurately, in line with the characteristics of the disease under study. For example, models with increasing complexity have been proposed to describe the fate of mastitis-causing E. coli in infected cows [23,24]. Models for co-evolutionary mechanisms between host and pathogens should be considered [38] if the time scale is longer than the one used in this study.

Other assumptions may be difficult to verify. For such assumptions, a set of arbitrary standard values for the parameters and different forms for equations should be tested in so-called sensitivity analyses. For example, the amount of loss in performance was assumed directly associated with pathogen load, although the most dramatic changes may occur at low or subclinical levels of disease, with diminishing effects of each additional parasite [39].

\section{Effectiveness analyses}

Two results from the effectiveness analyses are noteworthy, although they must be further evaluated in empirical studies. One is that the range of possible values of $\Delta \mathrm{E}_{\mathrm{P}}$ and $\Delta \mathrm{E}_{\mathrm{I}}$ for the different input parameters (Figure 5) is wide. This emphasizes the need to accurately model the infection process and its impact on the population before deciding on the most effective strategy. For example, increasing host tolerance is theoretically less effective for improving performance of populations infected with pathogens that cause minor rather than major mastitis. Indeed, pathogens causing minor mastitis are less virulent $(\omega)$ and less transmissible $(\beta)$ than those causing major mastitis [40], so modest advantages of high tolerance would be offset by the associated costs. Likewise, selecting for better resistance to mastitis would be effective to restrict the size of a population epidemic if animals are infected with bacterial strains that are likely to be killed by neutrophils [41], i.e. $\mu>0$ in equation 3 .
Another noteworthy observation is that least-squares means for $\Delta \mathrm{E}_{\mathrm{P}}$ were highest in highly tolerant populations, while $\Delta \mathrm{E}_{\mathrm{I}}$ did not change between different tolerance levels. This suggests that selection for increased tolerance would be effective under commercial constraints. This is different from models applied to natural populations that predict an increase in the overall incidence of infection as the frequency of tolerant hosts increases [38]. In natural populations, tolerant hosts survive longer than non-tolerant ones, thus keeping the disease longer in the population and increasing the risk of exposure to disease. Here, the model is for an endemic disease in a population under commercial contraints, in which non-tolerant animals are kept even if they are sick (no natural death, no culling). Consequently, the risk of exposure to disease does not change, even if the pathogen population size $(C)$ increases.

In general, little is known about tolerance mechanisms in animals but their study should provide a good foundation for insuring health over the long term. Indeed, in the long term, advantages of being tolerant should be greater than those associated with resistance. For example, in non-evolving pathogen populations, advantages of being resistant decrease in parallel with the decline in disease frequency, while the advantages of being tolerant are maintained, or even increase if disease frequency rises [42]. In evolving pathogen populations, improved host resistance will pressure pathogens to evolve better mechanisms to evade host defense processes, potentially resulting in cyclical co-evolutionary dynamics. In contrast, tolerance does not interact directly with the pathogen and should not induce selection for counter-adaptations, although elevated levels of tolerance may allow pathogens to be more virulent [43].

Practically, in bovine mastitis, it the degree of tolerance of an animal can be estimated by the amount of milk loss per bacteria present in the quarter (CFU) using a model adapted from that proposed by [2] for inbred strains of laboratory mice: 


$$
y_{i j}^{t}=\mu_{i}+b_{j} I_{i j}^{t}+B_{i j} I_{i j}^{t}+e_{i j}^{t}
$$

where $\mathrm{y}_{\mathrm{ij}}{ }^{\mathrm{t}}$ is the milk yield at time $\mathrm{t}$ of the $\mathrm{i}^{\mathrm{th}}$ cow (yield corrected for fixed and non-genetic random effects estimated from the genetic evaluation model) infected with $\mathrm{I}_{\mathrm{ij}}{ }^{\mathrm{t}}$, i.e. the bacterial load for bacterial species $j ; b_{j}$ is the average tolerance against bacteria of strain j; $B_{i j}$ describes individual random deviations from the average tolerance with $\mathrm{B}_{\mathrm{ij}} \sim \operatorname{IID~N}\left(0, \sigma^{2}{ }_{\mathrm{b}}\right)$; and $\mathrm{e}_{\mathrm{ij}}{ }^{\mathrm{t}}$ are residuals with $e_{i j}{ }^{t} \sim \mathrm{N}\left(0, V_{e}\right)$, where $V_{e}$ accounts for the non-independence between repeated $\mathrm{e}_{\mathrm{ij}}{ }^{\mathrm{t}}$. Such information could be collected from quarters of experimentally infected cows, as was done in the study of [44].

\section{Conclusions}

In summary, this paper presents a novel epidemic model to explore the effects of tolerance and resistance on performance and disease spread in a population. Although more research is necessary to validate the model and more empirical studies are needed to obtain values for the input parameters, the analytic approach can be used to find optimal strategies of disease control in commercial populations.

\section{Acknowledgements}

This study was supported by EADGENE (European Animal Disease Genomics Network of Excellence for Animal Health and Food Safety) and the University of Liege.

\section{Competing interests}

The authors declare that they have no competing interests.

Received: 13 October 2010 Accepted: 1 March 2011

Published: 1 March 2011

\section{References}

1. Jovanović S, Savić M, Živković D: Genetic variation in disease resistance among farm animals. Biotech Anim Husbandry 2009, 25:339-347.

2. Råberg L, Graham AL, Read AF: Decomposing health: tolerance and resistance to parasites in animal. Phil Trans R SOC B 2009, 364:37-49.

3. Medzhitov R: Damage control in host-pathogen interactions. Proc Nat/ Acad Sci 2009, 106:5525-15526.

4. Råberg L, Graham AL, Read AF: Decomposing health: tolerance and resistance to parasites in animal. Phil Trans $R$ Soc B 2009, 364:37-49.

5. Smith VH, Holt RD: Resource competition and within-host disease dynamics. Tree 1996, 11:386-389.

6. Baer B, Armitage SA, Boomsma JJ: Sperm storage induces an immunity cost in ants. Nature 2006, 441:872-875.

7. Kuukka-Anttila H, Peuhkuri N, Kolari I, Paananen T, Kause A: Quantitative genetic architecture of parasite-induced cataract in rainbow trout, Oncorhynchus mykiss. Heredity 2009, 104:20-27.

8. Little TJ, Killick SC: Evidence for a cost of immunity when the crustacean Daphnia magna is exposed to the bacterial pathogen Pasteuria ramos. $J$ Anim Ecol 2007, 76:1202-1207.

9. Read AF, Allen JE: Evolution and immunology: The economics of immunity. Science 2000, 290:1104-1105.

10. Coltherd JC, Bünger L, Kyriazakis I, Houdijk JGM: Genetic growth potential interacts with nutrition on the ability of mice to cope with Heligmosomoides bakeri infection. Parasitology 2009, 136:1043-1055.

11. Roberts MG, Heesterbeek JAP: Mathematical models in epidemiology. In Mathematical models. Edited by: Filar JA, Krawczyk JB. UNESCO-EOLSS Oxford; 2004: [http://www.eolss.net].
12. Detilleux JC: Neutrophils in the war against Staphylococcus aureus: Predator-prey models to the rescue. J Dairy Sci 2004, 87:3716-3724.

13. Li Y, Karlin A, Loike JD, Silverstein SC: A critical concentration of neutrophils is required for effective bacterial killing in suspension. Proc Natl Acad Sci USA 2002, 99:8289-8294.

14. Gillespie DT: Exact stochastic simulation of coupled chemical reactions. J Phys Chem 1977, 81:2340-2361.

15. Timms R, Colegrave N, Chan BHK, Read AF: The effect of parasite dose on disease severity in the rodent malaria Plasmodium Chabaudi. Parasitology 2001, 123:1-11.

16. SAS $^{\circledR}$ Institute: $S A S^{\circledast}$ User's Guide. Cary: SAS ${ }^{\circledR}$ Institute; 1998, Version 8.12.

17. Lanzas C, Ayscue P, Ivanek R, Gröhn YT: Model or meal? Farm animal populations as models for infectious diseases of humans. Nat Rev Microbiol 2010, 8:139-148.

18. Miller MR, White A, Boots M: The evolution of parasites in response to tolerance in their hosts: the good, the bad, and apparent commensalism. Evolution 2006, 60:945-956.

19. Brown JKM: Yield penalties of disease resistance in crops. Curr Opin Plant Biol 2002, 5:339-344.

20. Vandeputte-Van Messom G, Burvenich C, Roets E, Massart-Leën A, Heyneman R, Kremer WDJ, Brand A: Classification of newly calved cows into moderate and severe responders to experimentally induced Escherichia coli mastitis. J Dairy Res 1993, 60:19-29.

21. Zadoks RN, Allore HG, Barkema HW, Sampimom OC, Gröhn YT, Schukken YH: Analysis of an outbreak of Streptococcus uberis mastitis. J Dairy Sci 2001, 84:590-599.

22. Zadoks RN, Allore HG, Hagenaars TJ, Barkema HW, Schukken YH: A mathematical model of Staphylococcus aureus control in dairy herds. Epidemiol Infect 2002, 129:397-416.

23. Detilleux JC, Vangroenweghe F, Burvenich C: Mathematical model of the acute inflammatory response to Escherichia coli in intramammary challenge. J Dairy Sci 2006, 89:3455-3465.

24. White LJ, Schukken YH, Dogan B, Green L, Döpfer D, Chappell MJ, Medley GF: Modelling the dynamics of intramammary E. coli infections in dairy cows: understanding mechanisms that distinguish transient from persistent infections. Vet Res 2010, 41:13.

25. Gröhn YT, Wilson DJ, González RN, Hertl JA, Schulte H, Bennett G, Schukken $\mathrm{YH}$ : Effect of pathogen-specific clinical mastitis on milk yield in dairy cows. J Dairy Sci 2004, 87:3358-3374.

26. Gilligan CA, van den Bosch F: Epidemiological models for invasion and persistence of pathogens. Ann Rev Phytopathol 2008, 46:385-418.

27. Gross WP, Siegel PB, Pierson FW: Effects of genetic selection for high and low antibody response on resistance to a variety of disease challenge and the relationship of resource allocation. Avian Dis 2002, 46:1007-1010

28. Zuk M, Stoehr AM: Immune defense and host life history. Am Nat 2002, 160:S09-S28

29. Ingvartsen $\mathrm{KL}$, Dewhurst RJ, Friggens NC: On the relationship between lactational performance and health: is it yield or metabolic imbalance that cause production diseases in dairy cattle? A position paper. Livest Prod Sci 2003, 83:277-308.

30. Beldomenico PM, Begon M: Disease spread, susceptibility and infection intensity: vicious circles? Trends Ecol Evol 2010, 25:21-27.

31. Pujol JM, Eisenberg JE, Haas CN, Koopman JS: The effect of ongoing exposure dynamics in dose response relationships. PLoS Comput Biol Epub 2009, 5.

32. van der Goot JA, Koch G, de Jong M: Quantification of the effect of vaccination on transmission of avian influenza (H7N7) in chickens. Proc Natl Acad Sci USA 2005, 102:18141-18146.

33. Dybiec B: SIR model of epidemic spread with accumulated exposure. Eur Phys J 2009, 67:377-383.

34. Doeschl-Wilson AB, Brindle W, Emmans GC, Kyriazakis I: Unraveling the relationship between animal growth and immune response during micro-parasitic infections. PLOS ONE 2009, 4:e7508.

35. Brauer F: Epidemic models with heterogeneous mixing and treatment. Bull Math Biol 2008, 70:1869-1885.

36. Detilleux JC: Genetic management of infectious diseases: a heterogeneous epidemio-genetic model illustrated with $S$. aureus mastitis. Genet Sel Evol 2005, 37:437-453.

37. Nieuwhof GJ, Conington J, Bishop SC: A genetic epidemiological model to describe resistance to an endemic bacterial disease in livestock: application to footrot in sheep. Gen Sel Evol 2009, 41:19. 
38. Roy BA, Kirchner JW: Evolution dynamics of pathogen resistance and tolerance. Evolution 2000, 54:51-63.

39. Hawkins CD, Morris RS: Depression of productivity in sheep infected with Fasciola hepatica. Vet Parasitol 1978, 4:341-351.

40. White L, Lam TJ, Schukken YH, Green L, Medley G, Chappell MJ: The transmission and control of mastitis in dairy cows: a theoretical approach. Prev Vet Med 2006, 17:67-83.

41. Rambeaud M, Almeida RA, Pighetti GM, Oliver SP: Dynamics of leukocytes and cytokines during experimentally induced Streptococcus uberis mastitis. Vet Immunol Immunopathol 2003, 96:193-205.

42. Boots M: Fight or learn to live with the consequences. Trends Ecol Evol 2008, 23:248-250.

43. Svensson $E$, Råberg $L$ : Resistance and tolerance in animal enemy-victim coevolution. Trends Ecol Evol 2010, 25:267-274.

44. Vangroenweghe F, Rainart P, Paape M, Duchateau L, Burvenich C: Increase of Escherichia coli inoculum doses induces faster innate immune response in primiparous cows. J Dairy Sci 2004, 87:4132-4144.

doi:10.1186/1297-9686-43-9

Cite this article as: Detilleux: Effectiveness analysis of resistance and tolerance to infection. Genetics Selection Evolution 2011 43:9.

\section{Submit your next manuscript to BioMed Central} and take full advantage of:

- Convenient online submission

- Thorough peer review

- No space constraints or color figure charges

- Immediate publication on acceptance

- Inclusion in PubMed, CAS, Scopus and Google Scholar

- Research which is freely available for redistribution

Submit your manuscript at www.biomedcentral.com/submit 